\title{
On the Comparison of Effectiveness of Direct Instruction Method and Multimedia Instruction on students suffering from Special Learning Disorder along with Defects in Dictation
}

\author{
Samad Azimigaroosi ${ }^{1}$, Farshad Zhiean ${ }^{2, *}$, Hadi Farahmand ${ }^{3}$ \\ ${ }^{1}$ MA student, Department of Exceptional Children, University of Tehran, Tehran, IRAN \\ ${ }^{2}$ MA student, Department of Consulting, Tehran Science and Research Branch, Islamic Azad \\ University, Tehran, IRAN \\ ${ }^{3}$ MA student, Department of Clinical Psychology, University of Tehran, Tehran, IRAN
}

E-mail address: farshadzhian@gmail.com

Keywords: Dictation disorder, Special learning disorder, Direct instruction, Multimedia instruction.

\begin{abstract}
Dictation defect is one of the most rampant special learning disorders among students which accounts for around $30 \%$ of all the learning disorders. This research was conducted with the aim of comparing the effectiveness of the direct instruction and multimedia instruction on the dictation defects. The research methodology is of an experimental method along with pretest and posttest accompanied with a control group. After preparing necessary instruments for this research, i.e. the Wechsler intelligence test for children, Dictation instruction software and Karimi dictation tests, the number of 39 male third grade junior students was chosen through multistage sampling method from among Kermanshah schools and was randomly placed in three 13 people groups. A group was administered the independent variable of direct instruction while the second group was administered the independent variable of multimedia instruction whereas the control group did not receive any intervention. After collecting the students' dictation scores of all three groups in the pretest and posttest, data were analyzed via using the SPSS software and through Covariance analysis. Results revealed that direct instruction and multimedia instruction were meaningfully effective on the improvement of dictation disorder. Also, direct instruction was found to be more effective than the multimedia instruction.
\end{abstract}

\section{INTRODUCTION}

The major goal of all teachers, instructors and educational policy makers is learning, training and enriched learning among students. Among all students of all times, there are people who are diagnosed with problems in learning due to some internal and external obstacles. One of these problems and hindrances to learning is disability of special learning. The term learning disability was for the first time raised in1963. Prior to this date, people and children having such learning problems were known with terms such as intuition disabled, cerebral damaged, nervous damaged and the like (Kirk, 1963). This change of terms to inability and better than that disorder with special learning as due to the removability of the problems and instruction of this group of people. Children suffering from special learning experience delay or defect in the ability to learn fundamental educational skills. These problems once appear when their skills and progress are found to be much lower than the performance level in terms of age, training and intelligence scale (Seyed Mohamadi, 2014).

According to the U.S. Psychiatry Association, Diagnosis and statistical Fifth version, learning problems are considered for four "special" reasons: 1) these problems cannot be attributed to mental disability, overall growth delay, hearing and seeing disorders and neurologic a d kinetic disorders; 2) the intended learning disorder cannot be attributed to such factors as financial poverty or personal life within a poor neighborhood an unexplained and frequent absentia from school; 3) The intended learning problem cannot be attributed to neurologic disorders like brain seizures of children not being diagnosable from neurologic signs; 4) Learning problems might be limited to a skill or an academic area like reading single words or estimation of Multiplication table numbers and the like (Ganji, 2014). 
The phrase learning disorder is concerned with a single construct or disorder which is referred to defects in educational skills progress. This disorder has a non-homogenous nature where this non-homogeneity can be reflected in educational patterns, weakness and strength of information processing, and also in major classification systems as educational disorders of a special area like mathematical disorders, writing or reading (Kessi, 2012). The individual affected with special learning disorder along with disorders in mathematics has problems with mathematics assignments and concepts and may not comprehend mathematical terms, symbols and concepts. On the other hand, within the social learning disorder along with disorder in written expression, the individual has problems in spelling and using thee grammar properly. Also, people affected with the special learning disorder along with disorders in reading, delete, remove or replace words while reading. As a consequence, he reads them through pauses. This defect can result in children not to demonstrate sufficient progress in all types of textbooks.

From among several types of disorders, disorder in written expression (dictation) accounted for $29 \%$ of all the disabilities where families and teachers reported the emergence of this defect among the third and fourth grade students indefinitely. dictation is one of the educational skills and matters which is mainly taught during school era and creativity has no place therein whatsoever and it is only a pattern wherein composition, order, size and number of letters and signs are accepted as proper word forms. Children suffering from the dictation disorder have problems in this mentioned pattern. The act of writing dictation is a tricky activity for children due to the fact it is abstract.

In addition to that, the moat major causes for thee dictation defect are: insufficient inattention and care, weak movement (kinetic) skills, disorder in visual perceptions off letters and words, weakness in hearing and visual memory and difficulty communicating information from a sensory channel to the other sensory channel (Faryar and Derakhshaan, 2000). dictation, due to the fact it is abstract is tricky for the students because the written language is taught in the hierarchy of linguistic abilities after listening, speaking and reading. Hence, any problems in other areas mentioned will leave a negative effect in learning written language or dictation (Seif Naraghhi and Naderi, 2005). In accordance with the actual consequences and implications for the children suffering from dictation defect, it is clear that training and support are necessary for these children. Therefore, different methods like direct instruction and multimedia instruction could be used for helping them. Direct instruction is an educational method in which the teacher communicates the information immediately and directly within definite stages top students and the time is so adjusted that all the students could reach definite goals (Slawin, 2006). Direct instruction includes modeling, reinforcement, feedback, consecutive approximations and the learner being active (Joyce et al, 2000), exact designing of programs, navigated notes, graphical and pictorial organizers, visual representations and training of remembrance assistants (Watkins, 2003; Brigham and Brigham, 2001; Bulgarin et al, 2000; Dye, 2000). This method is confirmed by experimental researches results more than any other educational programs (Miartella et al, 2005; Suzan et al, 2005; Adams and Carnine, 2003; Watkins and Slowcam, 2004; Carnine et al, 2004). In 2005, in a research Diana, Richards and Nancy studied the results of 35 studies from 19720 to 2005 with regards to the effectiveness of direct instruction on educational progress of students suffering from learning defects and reported that most of the studies have demonstrated that direct instruction is an effective method compared to other educational methods for the children affected with this defect. While investigating 8 more studies, all the studies using the direct instructions methods reported to be showing some performance improvement $t$ for as much as $90 \%$. Albertin et al (2004), too, via reviewing 45 studies regarding the effectiveness of the direct instruction conclude that the direct instruction program would result in $90 \%$ performance improvement of children suffering from special learning defects (Margaret et al, 2007). Pirzadi et al (2012) concluded in a study that the direct instruction method of Phone awareness would leave some positive effects on the students suffering from reading defects and results in their increased skills of reading.

The Multimedia instruction method is another method which is applied for training and educating children suffering from learning disabilities and is to some extent derived from cognitive a $\mathrm{d}$ information processing theories. The multimedia learning is defined as learning through words 
(e.g. speaking or printed texts) and pictures (e.g. pictures, maps and shapes and animation) (Meyer, 2005). The multimedia programs draw the attention interests of learners; facilitates learning, provides objective and concrete experiences to the learners and help them learn fast (Fardanesh, 2003). Research results by Plass et al (2003) indicated that when students received two types of audio and written explanations while reading German texts scores higher in responding to the production test compared to the time when they received just one sort of information. These researchers found pout that written explanations could be found to be more effective in constructing words compared to visual explanations. Jones et al (1996) reported that when students received two types of audio and written explanations while reading French texts showed better performance in the test of recognition of written words compared to those who did not receive the explanation method (Chun et al, 1996). Musseli (2007), Hall et al (2005) (Quoted by Malakian and Akhoondi, 2006), Murray and Cloudier (2000), Malakian and Kharmide (2006), Ebrahimi (2005) too confirmed the effectiveness of different types of multimedia on learning disorder. In accordance with the importance of the duty for instruction and treatment of the students suffering from dictation defect, in order to avoid educational dropout, avoid a decline of self-esteem, students' isolation and dropout due to inability in this skill and other similar cases which result in a lack of progress, it is necessary to apply the best and most effective methods. This research was conducted with the aim of comparing the effectiveness of the direct instruction and multimedia instruction on the dictation defects.

\section{METHODOLOGY}

The research methodology is of an experimental method along with pretest and posttest accompanied with a control group. After preparing necessary instruments for this research, i.e. the Wechsler intelligence test for children, Dictation instruction software and Karimi dictation tests, the number of 39 male third grade junior students was chosen through multistage sampling method from among Kermanshah schools and was randomly placed in three 13 people groups.

\section{Measurement tools}

Wechsler intelligence test for children (WISC-R): In order to measure the IQ of the students, this test was applied. Therefore, all the subscales were applied because the major goal was to administer the test for determining the overall IQ score. The average reliability coefficients of the split half method for the verbal, practical and complete IQ were 0/94, 0/90 and 0/96 respectively. The retest coefficients were 0/93,0/90 and 0/95. The test validity, using the Wechsler intelligence test for children correlation estimation with the Stanford- Bine intelligence test was found to be the highest verbal scale correlation and the lowest cryptography was obtained (Anstazi, Translated by Braheni, 1992). In Iran, the reliability coefficient mean of $0 / 73$ was obtained t6hroiugh retest method. The overall IQ reliability coefficients in all age groups ranged from 0/79 to 0/96. In the split half method, the mean coefficients were $0 / 69$ and reliability coefficients of split half of tests was varying in between $0 / 42$ to $0 / 98$. The standard measurement error of the verbal, practical and overall IQ was around 5, 6 and 5 respectively. In the concurrent validity investigations of scale (WISC-R) with the WPPSI scale at a common age level, two scales, i.e. 6 to 6.5 , as many s 40 first grade students and preparation level were selected based on the same variables who were intended by the standardization sample. Correlation coefficients of the verbal, practical and overall IQ were $0 / 74$ and $0 / 85$ that are quite close to those as reported by Wechsler being $0 / 80,0 / 80$ and $0 / 82$ (Shahim, 1992).

\section{Dictation test}

To evaluate difficulties of dictation, there are many evaluation techniques available. Unofficial tests compared to tests published available, in accordance with the students' weak and strong points in dictation provide more usable information for the instruction of types students. Most of the time through unofficial instruction, profound information can be obtained for dictation progress. This technique is highly applicable and better determines dictation errors (Donald and 
Netiar, translated by Biabangard and Naeeniyan, 2003). Unofficial methods have been applied in Iran. For example, if a student has until now written 10 dictations, we take notes of all the mistakes he has committed in those dictations. Karimi (2005) considers investigation of three cases of students' dictations as sufficient for determine the type of problems related with dictations (Karami, 2005).

\section{Dictation test has been set in two sections:}

Section one, sentence test: this test contains 18 short sentences. To choose the content of pretest, the student's prior year textbook was used. The texts of pretest sentences for the third grade students were selected out of the second year textbook; pretest sentence texts for the students were chosen out of the third year textbook (Karimi, 2010). Section two, word test: This test contains 40 words. To choose the content of the pretest, the student's prior yar textbook as applied. Pretest words for students were selected pout of the second year textbook and the ;posttest words for the students were chosen out of the first half of the third year textbook (Karimi, 2010). Reliability of the dictation test was estimated at $0 / 98$ by the Cronbach's alpha coefficient (Karimi, 2010). Also, the content validity of the test was affirmed by the experts and instructors.

\section{RESULTS}

Table 1. Average and Standard deviation as distinguished by groups

\begin{tabular}{|l|l|l|l|l|l|l|}
\hline Variable & \multicolumn{2}{c}{ Intelligence } & \multicolumn{3}{c|}{ Pretest } & Avsttest \\
\hline Group & Average & SD & Average & SD & Average & SD \\
\hline Control & $96 / 53$ & $4 / 57$ & $10 / 23$ & $2 / 24$ & $9 / 53$ & $2 / 56$ \\
\hline $\begin{array}{l}\text { Direct } \\
\text { instruction }\end{array}$ & $97 / 76$ & $4 / 85$ & $10 / 15$ & $2 / 47$ & $17 / 57$ & $1 / 71$ \\
\hline $\begin{array}{l}\text { Multimedia } \\
\text { instruction }\end{array}$ & $98 / 69$ & $5 / 05$ & $10 / 96$ & $2 / 41$ & $16 / 30$ & $2 / 35$ \\
\hline
\end{tabular}

As seen in table (1) the average IQ coefficient and the dictation pretest score in all three groups of control, direct instruction and multimedia instruction are approximately equal. However, the average posttest scores of the direct instruction group and multimedia group have seen rises.

\section{Statistical presumption}

In order to confirm data, the covariance test and normality of data, the Leven's test and Kolmogorov-Smirnov test were applied.

Table 2. Equality test of the variance of variables errors

\begin{tabular}{|l|l|l|l|}
\hline F & Df1 & Df2 & Sig. \\
\hline $0 / 051$ & 2 & 36 & $0 / 951$ \\
\hline
\end{tabular}

The Leven's test findings indicated that the variance of variables errors in different groups showed no significant difference $\left(\mathrm{P}>0 / 05\right.$ and $\mathrm{F}_{2}$ and $\left.36=0 / 051\right)$.

Table 3. Test of data normality

\begin{tabular}{|l|l|l|}
\hline Group & $\begin{array}{l}\text { Z statistic value, } \\
\text { Kolmogorov-Smirnov }\end{array}$ & Sig. \\
\hline Control & $0 / 674$ & $0 / 754$ \\
\hline Direct instruction & $0 / 497$ & $0 / 966$ \\
\hline Multimedia instruction & $0 / 490$ & $0 / 970$ \\
\hline
\end{tabular}

The Kolmogorov-Smirnov test results indicated that data under analysis were normal. 


\section{Inferential findings}

Table 4. Covariance analysis

\begin{tabular}{|l|l|l|l|l|l|l|}
\hline Variable & $\begin{array}{l}\text { Square } \\
\text { sum }\end{array}$ & $\begin{array}{l}\text { Freedom } \\
\text { degree }\end{array}$ & $\begin{array}{l}\text { Square } \\
\text { average }\end{array}$ & F & Sig. & Squares \\
\hline Pretest & $76 / 25$ & 1 & $76 / 25$ & $25 / 37$ & $0 / 001$ & $0 / 42$ \\
\hline Group & $469 / 37$ & 2 & $234 / 68$ & $78 / 09$ & $0 / 001$ & $0 / 82$ \\
\hline Error & $105 / 17$ & 35 & $3 / 00$ & - & - & - \\
\hline
\end{tabular}

Covariance analysis results (ANCOVA) indicated that there is a significant difference between research groups (direct, control and multimedia) $(\mathrm{p}<0 / 05, \mathrm{~F}=2 / 38=78 / 09)$.

Table 5. Pair comparative test results with Bonferroni method

\begin{tabular}{|l|l|l|l|}
\hline Groups & Control & Direct instruction & $\begin{array}{l}\text { Multimedia } \\
\text { instruction }\end{array}$ \\
\hline Control & - & & \\
\hline Direct instruction & $-8 / 06^{* *}$ & - & - \\
\hline $\begin{array}{c}\text { Multimedia } \\
\text { instruction }\end{array}$ & $-6 / 32^{* *}$ & $1 / 76^{*}$ & - \\
\hline
\end{tabular}

Covariance analysis results indicated that direct ionstrc8ution has been effective on the dictation defects of students and the discrepancy of average in the posttest of the group with the direct instruction along with the control group indicates effectiveness of this teaching method on the dictation disorder $(\mathrm{P}<0 / 001)$.

\section{CONCLUSION}

Dictation defect is one of the most rampant special learning disorders among students which accounts for around $30 \%$ of all the learning disorders. This research was conducted with the aim of comparing the effectiveness of the direct instruction and multimedia instruction on the dictation defects. Findings revealed that direct instruction has been effective on the improvement of students' performance. This finding is conformity with those of Margaret, Fores and Keller (2007), Maclog and Kimberly (2007), Miartella and Sowler (2005), Suzan, Barbara and John (2005), Diana, Richards and Nancy (2005), Watkins and Slowcam (2004), Carnine, Silber and Cumby and Trevor (2004), Albertin, Meyers and Ziegler (2004), Ovens, Fredrick and Shippen (2004), Adams and Carnine (2003), Simpson (1991), Elizabeth (1990), and Karimi (2010). The finding has also been in line with researches regarding effectiveness of multimedia on instruction and also researches by Piview, 2006; Meyer, 2005; Clark, Piview quoted by Meyer, 200; Gabiel, 2001; Martines, 1997 quoted by Segeyeer, 2001. There are several factors which result ion effectiveness of the direct instruction method on students affected with learning disorder. Firstly, the fact that this educational method has been derived from processing-process researches in which both the teacher and students are put under study so that it becomes clear that teachers' educational activities will maximize education and hence the needs of the students having defects will be studies so that it is determined that how education and instruction should be designed in such a way it is of interest for maximum return. Regarding children suffering from learning disorder, this study is highly helpful because this group of students have special needs and care for instruction. The other reason for this educational method is designing, implementation and special evaluation of this educational meth0dd (Slawin, 2006; Seyf, 2009, Joyce et al, 2004 quoted by Kurd Noghabi, 2008).

The Multimedia instruction method was found to be effective on the improvement of students; dictation and several factors could be cited for this appropriate return. Firstly, far from theorization, one can consider the success of this method as being separate from older methods. Because, this method, with the emergence of modern technologies in the area of audio and visual 
media and especially in the area of computer technology have resulted in concrete and objective experiences, attraction for the learner, speed in reception and access to this kind of instruction, coordination with the needs of the students, compatibility with the ability level and progress of the students (Meyer, 2005). Of other factors for the success of this instruction based method, one can refer to learning as being meaningful. Learning in this manner could be called meaningful because learners via this method have managed to obtain a mental coordinated picture of information several sources (i.e. voice, picture, animation, films and computer plays) and to give meaning to the contents presented and thus result in learning of words as being fixed. With addition of attractive songs and voices being appropriate with the age of the child, also various games and animations related with the subject matter under education, other mental learning centers of the child will be engaged within the learning process and thus it will reinforce learning capacity. As Gabiel (2001) has pointed it of other factors for the success of this instruction method, the possibility of repetition off this sort of instruction without fatigue and tiresome, engagement of all students in the multimedia, and receiving feedbacks from them and existence of an interaction between many of 6he teachers and students.

\section{References}

[1] Ebrahimi, Zahra (2005), Comparison of the effects of interactional (CD) and noninteractional media (films) on speed and sustainability of learning mathematics among junior female students, Tehran's district 17, in the educational year of 2002-2003, M.A. thesis, University of Allame Tabatabaee, Faculty of Psychology and educational Sciences

[2] Anstazi, Andre, (1993), Psychometrics, (Tr. Mohamad Taghi Braheni), University off Tehran press

[3] Pirzadi, Hojjat; Ghobari Bonab, Bagher; Shokoohi Yekta, Mohsen; Yar Yari, Fereydoon; Hasanzade, Saeed and Sharifi, Ahmad (2013), Effects of direct instruction of phone awareness on progress of reading among students affected by reading disorders, Hearing journal, 1(21)

[4] Kharamide, Zahra (2007), Comparison of effects of instruction through interactional and non-interactional multimedia on increasing special, accuracy of learning Biology textbook among first grade junior female students, District 19, educational year of 2006-2007, M.A. thesis, University of Allame Tabatabaee, Faculty of Psychology and educational Sciences

[5] Donald, Nettiar (2000), Educating students with learning and behavioral problems, Tr. Esmaeel Biabangard and Naeeniyan (2003), Tehran: Department for Education of Exceptional Children

[6] Seyed Mohamdi, Yahya (2014), Mental Psychopathology based on DSM-5, Tehran: Ravan publication

[7] Seyf Naraghi, Maryam and Naderi, Ezzatollah (2005), Special disabilities in leaning, Tehran: Makyal cultural publication institute

[8] Seyf, Aliakbar (2009), Modern educational psychology, Psychology of learning and education, $6^{\text {th }}$ edition, Tehran: Doran publication

[9] Shahim, Sima (1993), Use of Wexler IQ scale for Children, (WISC-R) in Iran, Psychological researches journal, 1-28-40

[10] Fardanesh, Heshmat (2003), Theoretical basics of educational technology, Tehran: SAMT

[11] Faryar, Akbar; Rakhshaan, Fereydoon (2000), Learning disabilities; theoretical principles, diagnosis and educational strategies, Tehran: Mabna publication 
[12] Karami, Jahangir, (2005), Exploring epidemiology of dictation learning defects an d effects of multisensory treatment method on reduction of this inability among elementary students, Ahvaz, PhD dissertation, University of Shahid Chamran, Ahvaz

[13] Karimi, Behrooz, (2010), Comparison of effectiveness of direct instruction and phonology awareness on dictation defect, M.A. thesis, University of Allame Tabatabaee, Faculty of Psychology and educational Sciences

[14] Karimi, Yousef, (2005), Learning disorders, Tehran: Savalan publication

[15] Ganji, Mehdi (2014), Psychology of Exceptional children based on DSSM-5, Tehran: Savalan publication

[16] Adams, G., and Carnine, D. (2003). Direct instruction. InH. L. Swanson, K. R. Harris, \& S. Graham (Eds.), Handbook of learning disabilities (pp. 403-416). New York: Guilford Press.

[17] Allbritten.D.,Mainzer,R.And Ziegler,D.(2004).Will Student With Disablities Be Scapegoate For School Failures? Educational Horizons, 82, 153- 600.

[18] Brigham, R., and Brigham, M. (2001). Current practice alerts: Mnemonic instruction. Reston, VA: Division for Learning disabilities and Division for Research of the Council for Exceptional Children.

[19] Bulgren, J. A., Deshler, D. D., Schumaker, J. B., and Lenz, B. K. (2000). The use and effectiveness of analogical instruction in diverse secondary content classrooms. Journal of Educational Psychology, 16, 426-441.

[20] Carnine, D., Silbert, J., Kame'enui, E., \& Tarver, S. (2004). Direct instruction reading (4th ed.). Upper Saddle River, NJ: Pearson.

[21] Casey, J., (2012). A Model To Guide the Conceptualization, Assessment, and Diagnosis of Nonverbal Learning Disorder. Canadian Journal of School Psychology. 27(1), 35-57.

[22] Chun, D. M. \& Plass, J. L. (1996). Effects of multimedia annotations on vocabulary acquisition. The Modern Language Journal, 80 (2), 183- 198.

[23] Dye, G. A. (2000). Graphic organizers to the rescue! Helping students link- and rememberinformation. Teaching Exceptional Children, 32, 72-76. Education, 33, 131- 152.

[24] Jones, L., \& Plass, J. (2002). Supporting listening comprehension and cquisition in French with multimedia annotations. The Modern Language Journal, 86(4), 546-561.

[25] Joyce, B., Weil, M., and Calhoun, E. (2000). Models of teaching. (6th ed.). Boston: Allyn \& Bacon.

[26] Kirk, S. A. (1963). Behavioral diagnosis and remediation of learning disabilities. In proceedings the conference on the problems of the perceptually Handicapped child. Evanston, IL: Fund for the Perseptual Handicapped Child.

[27] Margaret, M. Flores., and Maria, Kaylor. (2007). The Effects of a Direct Instruction Program on the Fraction Performance of Middle school students At - risk for failure in mathematics.

[28] Mayer, R. E. (2002). Cognitive Theory and the Design of Multimedia Instruction: An Example of the Two-Way Street Between Cognition and Instruction. New Directions for Teaching and Learning, 89, 55-71.

[29] Mayer, R. E. (2003). The promise of multimedia learning: Using the same instructional design methods across different media. Learning and Instruction, 13, 125-139. 
[30] Mayer, R. E. (2005). Cognitive theory of multimedia learning. In R. E. Mayer (Ed.), The Cambridg handbook of multimedia learning (pp: 31-48). Cambridge: Cambridge University Press.

[31] Miartella, R.C. and Waldron - soler, K.M. (2005). Language for writing program evaluation. Journal of Direct Insruction ,5, 81-96.

[32] Plass, J. L., Chun, D. M., Mayer, R. E., \& Leutner, D. (2003). Cognitive load in reading a foreign language text with multimedia aids and the influence of verbal and spatial abilities. Computers in Human Behavior 19 (2003), 221-243.

[33] Slavien Robert E. (2006). Educational psychology: Theory and Practice 8th ed.

[34] Susan, G. Magliaro., Barbara, B. Lockee., and John, K. Burton. (2005). Direct Instruction Revisited: A Key Model for Instructional Technology, ETR \& D, Vol. 53. 41 -55.

[35] Watkins, C. L. (2003). The components of direct instruction. Jurnal of Direct Instruction, 3, 75-110.

[36] Watkins, C. L., and Slocum, T. A. (2004). The components of Direct Instruction. In N. E. Marchand- Martella, T. A. Slocum, \& R. C. Martella (Eds.), Introduction to Direct Instruction. Boston, MA: Allyn \& Bacon, (pp. 28-65). 